\title{
Multivariate and univariate asymmetrical analyses in environmental impact assessment: a case study of Mediterranean subtidal sessile assemblages
}

\author{
Antonio Terlizzi ${ }^{1, *}$, Lisandro Benedetti-Cecchi ${ }^{2}$, Stanislao Bevilacqua ${ }^{1}$, \\ Simonetta Fraschetti ${ }^{1}$, Paolo Guidetti ${ }^{1}$, Marti J. Anderson ${ }^{3}$ \\ ${ }^{1}$ Laboratorio Zoologia e Biologia Marina, Dipartimento Scienze e Tecnologie Biologiche ed Ambientali, Università di Lecce, \\ CoNISMa, 73100 Lecce, Italy \\ ${ }^{2}$ Dipartimento di Scienze dell'Uomo e dell'Ambiente, Università di Pisa, Via A. Volta 6, 56126 Pisa, Italy \\ ${ }^{3}$ Department of Statistics, Tamaki Campus, University of Auckland, Private Bag 92019, Auckland, New Zealand
}

\begin{abstract}
Characterizing the potential effects of human activities on natural systems is a central problem in applied ecology. This requires the development of analytical procedures able to separate human perturbation from natural spatio-temporal variability displayed by most populations. BeyondBACI experimental designs provide a framework to address these issues but, to date, their use is limited to the analysis of human impacts on the abundance of single species or other univariate measures. Here, we describe in detail an asymmetrical design that included 1 impact location $(I)$ and a set of 3 controls $(C s)$, sampled at a hierarchy of spatial scales 4 times over a period of 15 mo. We focused on shallow subtidal assemblages of sessile organisms exposed to sewage discharge along a stretch of coast in southern Italy. The purpose of this paper is to illustrate (1) the comparison of variance components for the assessment of impacts and (2) the use of recently developed multivariate methods (distance-based premutational MANOVA) in the analysis of multivariate species data in response to a complex asymmetrical design. Results indicated that temporal changes in the whole assemblage at $I$ were distinct from those occurring at $C S$, and that the nature of this difference (although not its size) was fairly consistent through time. A suite of taxa was identified as important in characterizing the differences found between $I$ and Cs. Some algae (e.g. Colpomenia sinuosa, Gelidium sp. and Pterocladiella sp.), in particular, occurred uniquely at $I$. Univariate analyses indicated significant Time $\times I$-v-Cs interactions for several taxa, and significantly smaller spatial variation at the scale of quadrats at $I$ compared to Cs. In contrast, the small-scale spatial variation in the number of taxa was significantly greater at $I$ than at $C$. The findings of this study have important implications for future multivariate and univariate analyses in environmental impact assessment.
\end{abstract}

KEY WORDS: BACI designs $\cdot$ Multivariate analysis $\cdot$ PERMANOVA $\cdot$ Permutation tests $\cdot$ Monte Carlo tests $\cdot$ Sewage discharge $\cdot$ Subtidal sessile assemblages $\cdot$ Mediterranean Sea

\section{INTRODUCTION}

Interactions between physical and biological factors can cause strong fluctuations in the patterns of distribution and abundance of marine biological assemblages. The quantitative description of such patterns is the basis for understanding processes that structure assemblages of organisms (Andrew \& Mapstone 1987,
Underwood \& Chapman 1998). Anthropogenic disturbance has the potential to alter patterns of species' composition and abundance at various spatial and temporal scales. A crucial step for detecting the effects of human activities on natural systems is the development of a suite of reliable, rapid and cost-effective analytical procedures that are able to distinguish between natural and human-induced changes. 
Experimental ecology has strongly influenced the field of environmental impact assessment, and considerable efforts have been devoted to improve the logical structure and the analytical procedures for assessment of environmental impacts (Stewart-Oaten et al. 1986, Underwood \& Peterson 1988, Fairweather 1991, Osenberg et al. 1994). Various sampling designs and analytical methods have been proposed to detect changes in single response variables. The BACI (Before/AfterControl/Impact) approach, in particular, has been proposed to tease apart the effects of human impacts from natural variability (Osenberg \& Schmitt 1996). Since the first formulation of BACI experimental designs (Green 1979), various improvements have been developed to deal with cases of spatial and temporal confounding (Bernstein \& Zalinski 1983, Stewart-Oaten et al. 1986, Eberhardt \& Thomas 1991). The development of beyond-BACI designs (Underwood 1991), in particular, has led to significant advances in the detection of impacts associated with human activities. Such designs use multiple control locations and the data are usually analyzed with asymmetrical analysis of variance due to the presence of a single disturbed location. In this approach, an impact, if it exists, can be detected as a statistical interaction in the difference between the impacted and control locations from before to after the disturbance. Thorough discussions of beyondBACI designs, including several examples and their interpretation, are provided by Underwood (1991, 1992, 1993, 1994). Further examples of the performance of BACI and beyond-BACI procedures are illustrated by Hewitt et al. (2001), whereas BenedettiCecchi (2001) discussed an approach based on Monte Carlo simulations to optimize such complex designs. Stewart-Oaten \& Bence (2001) discussed a number of potential problems of beyond-BACI procedures and emphasized a model-based philosophy to the analysis of impacts.

A possible advantage of beyond-BACI designs is that they can be modified and applied in tests of impact when no data have been obtained before the purported impact and, thus, only 'after' data are available. These 'ACI' (After-Control/Impact) designs, though more limited in establishing cause-effect relationships between human interventions and responses of populations, have been widely used in environmental impact studies (Chapman et al. 1995, Roberts 1996, Lardicci et al. 1999, Guidetti et al. 2002). More specifically, in the absence of 'before' data, it may be possible to detect consistent differences between 1 or more impact locations and several control or reference locations, although it is generally not possible to attribute causation to any particular event, historical or ongoing, for such differences. A detailed description of how to deal with asymmetrical data and a discussion of the problems associated with detecting impacts when only 'after' data are available are provided by Glasby (1997).

Non-parametric multivariate procedures have emerged in recent years, providing useful statistical methods that have been widely adopted for analyzing post-impact studies (Smith et al. 1990, Clarke 1993). An important feature of these methods is that they do not require the assumption of multivariate normality. This is a requirement of more traditional multivariate methods such as multivariate analysis of variance (MANOVA), but such an assumption is very unlikely to be met by data consisting of counts of species' abundances or percentage cover of organisms (Legendre \& Legendre 1998).

Some multivariate extensions to BACI designs were presented by Kedwards et al. (1999), who described an approach based on canonical correspondence analysis (ter Braak 1986) and using randomization tests to assess significance. Faith et al. (1991) also described a multivariate BACI analysis based on a gradient model. Although these approaches may provide some useful tests, they are either limited through the reduction of dimensionality required or by their inability to handle complex experimental designs.

In fact, some of the most widely used non-parametric multivariate methods (e.g. ANOSIM, Clarke 1993), which are extremely elegant and useful for many kinds of ecological applications, do not allow tests of multivariate interactions and cannot be used to analyze complex experimental designs. Asymmetrical beyondBACI designs are, nevertheless, very important in current scientific environmental impact assessment. These designs generally have many factors (often 3 or more), including mixtures of fixed and random effects and hierarchical or interactive spatial and/or temporal structures (Underwood 1991, 1994).

Recently, new methods have been developed to investigate multispecies responses in multifactorial ecological experiments (Legendre \& Anderson 1999, Anderson 2001a, McArdle \& Anderson 2001). These new procedures can be based on any dissimilarity measure of choice and use permutation methods, and so do not assume multivariate normality. More particularly, they also allow tests of interactions or of any other term or contrast in a structured multifactorial design or model. These are suitable techniques for the analysis of multivariate data in response to beyond-BACI or ACI designs, but their application in the assessment of environmental impacts has not yet been done.

Large and growing human populations in the coastal areas of all continents exert the most important pressure on coastal ecosystems, particularly through the disposal of wastes to coastal waters (Koop \& Hutchins 1996). Sewage disposal to oceans is generally seen as a 
cost-effective way of dealing with human wastes without causing noticeable problems because of the dilution of pollutants in seawater. However, much of the eutrophication occurring worldwide has been related to increased nitrogen loads attributable to the discharge of sewage (Costanzo et al. 2001). Sewage effluent, often discharged from outfalls into shallow subtidal habitats, can result in significant effects on coastal biota (Pearson \& Rosenberg 1978, Smith et al. 1999, Guidetti et al. 2003).

Sewage may cause changes in abundance, biomass or diversity of benthic organisms (Pearson \& Rosenberg 1978), bioaccumulation of organic and inorganic compounds (Phillips 1978) and changes in trophic interactions among species (Otway et al. 1996). Structured sampling designs are increasingly used to quantify the effects of sewage on assemblages of rocky shores, both in intertidal (Archambault et al. 2001) and subtidal habitats (Roberts et al. 1998).

In this study, we focused on shallow subtidal assemblages of sessile organisms exposed to sewage along a stretch of coast in southern Italy. Results of preliminary studies in this area showed that the outfall heavily influenced the pattern of spatial distribution of sessile macrobenthos (Terlizzi et al. 2002) and rocky reefassociated fish (Guidetti et al. 2002). Here, we describe in detail an asymmetrical ACI design, including 1 impact location and a set of 3 control locations, sampled at a hierarchy of spatial scales and at several times. The purpose of the paper is (1) to illustrate additional applications of univariate analyses in the assessment of impacts through comparisons of variance components and (2) to demonstrate the use of recently developed multivariate methods (i.e. distance-based permutational MANOVA, Anderson 2001a) in the analysis of multivariate species data in response to such a design.

\section{MATERIALS AND METHODS}

Study sites and sampling design. The outfall $\left(17^{\circ} 55^{\prime}\right.$ $\left.33^{\prime \prime} \mathrm{N}, 40^{\circ} 11^{\prime} 20^{\prime \prime} \mathrm{E}\right)$ serves about 30000 inhabitants. The volume discharged ranges from 200 to $600 \mathrm{~m}^{3} \mathrm{~h}^{-1}$. Wastewaters are biologically and chemically treated before being discharged, although technical problems often prevent the complete depuration of water.

Sampling was undertaken at a depth of approximately $5 \mathrm{~m}$ at 4 locations: the outfall and 3 reference (or control) locations (Fig. 1). The putatively impacted location at the outfall (hereafter indicated as $I$ ), was located within a $400 \mathrm{~m}$ radius of the point of discharge. It was characterized by a wave-exposed calcarenitic rocky plateau extending from the water surface to about $10 \mathrm{~m}$ depth on fine sand with a gentle-medium

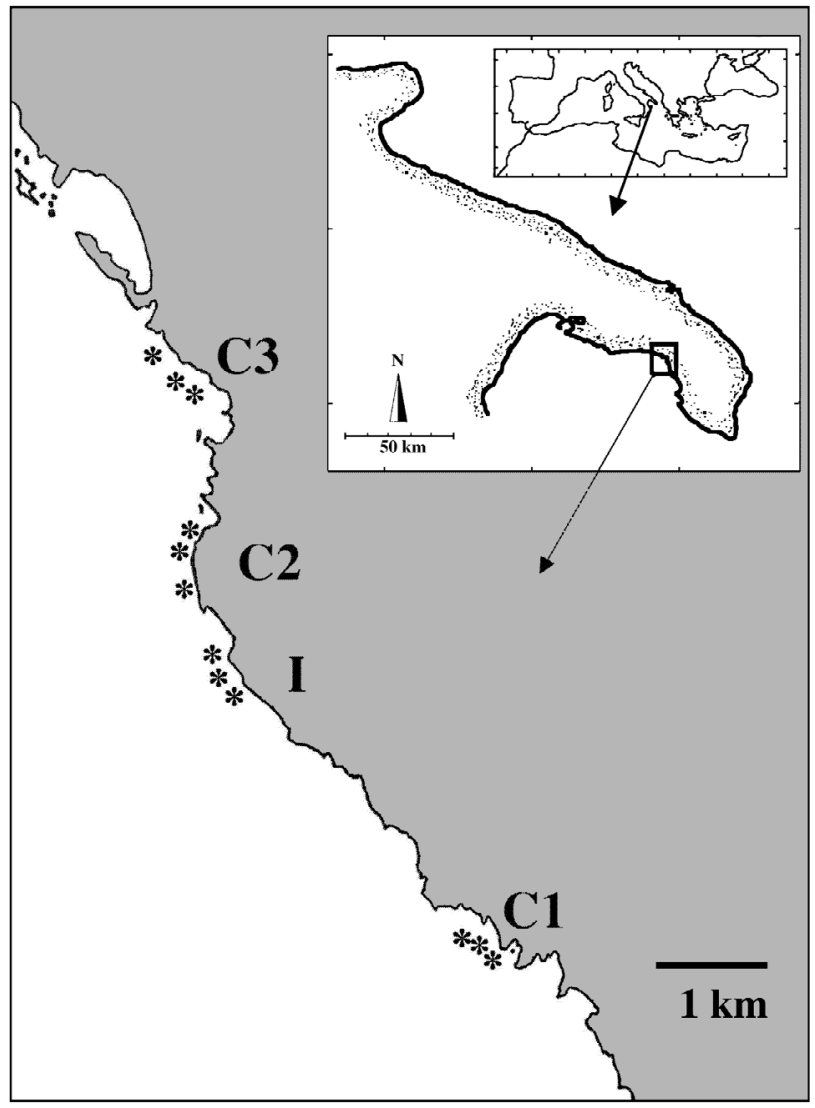

Fig. 1. Study area and position of disturbed $(I)$ and control (C1, C2 and C3) locations in southern Italy. *: position of sites in each location

slope. Control locations (hereafter indicated as Cs) were chosen at random from a set of possible locations separated by at least $3 \mathrm{~km}$, to provide comparable habitats to those occurring at the outfall (in terms of biological assemblages, type and slope of the substrate and exposure of waves). They were also chosen such that at least 1 control location occurred on either side of the outfall. Three sites (approximately 100 to $300 \mathrm{~m}$ apart) were randomly selected at each location and photographic records were taken at each site. The photographic equipment consisted of a Nikonos $\mathrm{V}$ underwater camera, $28 \mathrm{~mm}$ focal length, close-up macro system and a couple of SB 105-Nikon electronic strobes. In order to prevent problems due to loss of observation units, 13 randomly located quadrats of $16 \times$ $23 \mathrm{~cm}$ (total area $0.4 \mathrm{~m}^{2}$ ) were photographed at each site and a random subset of 10 of these were used in the analyses. Sampling was repeated on 4 randomly selected occasions, separated by at least 2 mo, over a period of 15 mo (May and July 2000, February and August 2001), yielding a total of 480 observation units.

Analysis of slides and taxonomic discrimination. The slides were analyzed under a binocular micro- 
scope by superimposing a transparent subdividing grid of 24 equally sized squares. For each slide, percent cover values of algae and sessile animals were estimated by assigning a score to each taxon ranging from 0 to 4 within each square and adding up these 24 values. Organisms filling less than 1/4 square were given an arbitrary value of 0.5 (Dethier et al. 1993). Final values were expressed as percentages. No attempt was made to count motile and/or fast-moving animals (e.g. gastropods, ophiuroids and amphipods).

Destructive samples were also collected to aid the identification of taxa in the laboratory. Prior to collection, a close-up $80 \mathrm{~mm}$ photo was taken of each taxon. Specialists assisted in the taxonomic identification of organisms.

Data were collapsed into morphological groups to obtain sufficiently large values for univariate analyses. The following groups were considered: encrusting calcified red algae (including Lithophyllum frondosum, $L$. incrustans, Mesophyllum alternans and Peyssonnelia polymorpha), filamentous brown algae (genera Ectocarpus and Sphacelaria), filamentous green algae (genera Bryopsis, Cladophora and Chaetomorpha), encrusting sponges (Crambe crambe, Phorbas spp. and Spirastrella cunctatrix) and encrusting bryozoans (Calpensia nobilis, Reptadeonella violacea, Schizobrachiella sanguinea, Schizoporella dunkeri). In addition, univariate analyses were used to analyze the total number of taxa per observation unit. Multivariate analyses were based on a total of 58 taxa. Of these, 39 were identified as species. Due to problems of taxonomic identification from slides, the remaining ones were included in the analyses at coarser levels of taxonomic resolution. Six were kept at the level of genera, 6 as families (e.g. Gelidiaceae, Serpulidae, Clionidae), 1 as a class (i.e. Hydrozoa) and 6 as morphological groups (e.g. encrusting calcified red algae, green filamentous algae, brown filamentous algae, etc.).

Univariate analyses. Univariate data were analyzed using asymmetrical analysis of variance (ANOVA). The model consisted of 3 factors (Table 1): Time (4 levels, random), Location (random, crossed with Time, with 1 disturbed and 3 control locations) and Site (3 levels, random, nested in Location), with $\mathrm{n}=10$ observations per combination of factor levels. As there was only 1 location that was purportedly 'impacted', being near the outfall, this is an asymmetrical design (Underwood 1991, 1994). In addition, no data were collected before the establishment of the outfall, thus the design could perhaps be described as a beyond-ACI design (see Glasby 1997). The individual terms in the analysis of variance (ANOVA) model, along with their associated degrees of freedom and expected values for mean squares, are given in Table 1. For analysis, the Location term, having 4 levels and 3 degrees of freedom, was partitioned into 2 portions: the 1 degree-offreedom contrast of Impact versus Controls (I-vs-Cs) and the variability among $C s$. Note that the $I$-v- $C s$ contrast must include variability among locations as part of its expected mean square (Table 1 ). The Time $\times$ Location $(\mathrm{T} \times \mathrm{L})$ mean square was similarly divided into 2 portions: a Time $\times I$-v-Cs $(\mathrm{T} \times I$-v-Cs $)$ and a Time $\times C s$ $(\mathrm{T} \times \mathrm{Cs})$ interaction, whereas the overall mean squares of the terms Site(Location) (S[L]) and $\mathrm{T} \times \mathrm{S}(\mathrm{L})$ were partitioned into $\mathrm{S}(I), \mathrm{S}(C S), \mathrm{T} \times \mathrm{S}(I)$ and $\mathrm{T} \times \mathrm{S}(C s)$ terms, respectively. Finally, the residual variation was divided into 2 parts: the variability for observations within $I(\operatorname{Res} I)$ and variability for observations within Cs (Res Cs) (Table 1).

Denominators for $F$ ratios were identified following the logic of beyond-BACI designs (see particularly Underwood 1992). However, tests of terms that involved sources of variation specific for $I$ or Cs were constructed using the natural denominator for that term, not the pooled one (Table 1). For example, the $\mathrm{T} \times \mathrm{S}(I)$ interaction was tested over Res $I$ rather than the overall residual variation. Although this procedure involves a reduced number of degrees of freedom in the denominator of $F$, possibly decreasing statistical power, it takes into account possible differences between $I$ and $C S$ in spatial (and temporal) variance. Using the overall residual variation as denominator makes the assumption that the variance among quadrats at $I$ and $C s$ is the same, which may not be the case if an impact affects small-scale spatial patterns.

In order to test hypotheses concerning effects on variances, rather than mean effects, variance components were obtained using restricted maximum likelihood (REML) estimators (Searle et al. 1992). REML was used rather than the usual ANOVA estimators to avoid the potential problem of obtaining negative estimates. This procedure was used to estimate spatial variances at the scale of quadrats and sites, in addition to the $\mathrm{T} \times$ $\mathrm{S}(\mathrm{L})$ component, separately for $I$ and Cs.

Linear combinations of mean squares, such as are used to estimate variance components, do not always have tractable known statistical distributions for relevant null hypotheses (Searle et al. 1992). However, obtaining confidence intervals for individual variance components is important for hypothesis testing in the context of impact assessment. More particularly, we may wish to compare variation at the impact location versus that at the controls at more than 1 spatial scale. Various methods have been proposed to obtain approximate confidence intervals (e.g. Searle et al. 1992, Neter et al. 1996), but there is no general consensus on their validity. Here, we took an alternative approach and obtained confidence intervals for individual variance components using bootstrapping (Efron \& Tibshirani 1993). Bootstrap confidence intervals were 
Table 1. Asymmetrical analysis of variance comparing a disturbed location $(I)$ with control locations $(C s)$; in this study there were $a=4$ times of sampling, $b=4$ locations (the disturbed location and 3 controls), $c=3$ sites in each location and $n=10$ replicate quadrats in each site

\begin{tabular}{|c|c|c|}
\hline Source of variation & df & Expected mean square \\
\hline Time $=\mathrm{T}$ & $a-1$ & $\sigma_{\mathrm{e}}^{2}+n \sigma_{\mathrm{T} \times \mathrm{S}(\mathrm{L})}^{2}+c n \sigma_{\mathrm{T} \times \mathrm{L}}^{2}+b c n \sigma_{\mathrm{T}}^{2}$ \\
\hline Location $=\mathrm{L}$ & $b-1$ & $\sigma_{\mathrm{e}}^{2}+n \sigma_{\mathrm{T} \times \mathrm{S}(\mathrm{L})}^{2}+c n \sigma_{\mathrm{T} \times \mathrm{L}}^{2}+a n \sigma_{\mathrm{S}(\mathrm{L})}^{2}+a c n \sigma_{\mathrm{L}}^{2}$ \\
\hline${ }^{\mathrm{k}} I-\mathrm{v}-C s$ & 1 & $\sigma_{\mathrm{e}-I}^{2}+n \sigma_{\mathrm{T} \times \mathrm{S}(I)}^{2}+c n \sigma_{\mathrm{T} \times I-\mathrm{v}-C s}^{2}+a n \sigma_{\mathrm{S}(I)}^{2}+a c n \sigma_{\mathrm{L}}^{2}+a c n \beta_{I-\mathrm{v}-C s}^{2}$ \\
\hline${ }^{\mathrm{j}} \mathrm{Cs}$ & $b-2$ & $\sigma_{\mathrm{e}-C s}^{2}+n \sigma_{\mathrm{T} \times \mathrm{S}(C s)}^{2}+c n \sigma_{\mathrm{T} \times C s}^{2}+a n \sigma_{\mathrm{S}(C s)}^{2}+a c n \sigma_{C s}^{2}$ \\
\hline${ }^{\mathrm{i}} \operatorname{Site}(\mathrm{L})=\mathrm{S}(\mathrm{L})$ & $b(c-1)$ & $\sigma_{\mathrm{e}}^{2}+n \sigma_{\mathrm{T} \times \mathrm{S}(\mathrm{L})}^{2}+a n \sigma_{\mathrm{S}(\mathrm{L})}^{2}$ \\
\hline${ }^{\mathrm{h}} \mathrm{S}(I)$ & $c-1$ & $\sigma_{\mathrm{e}-I}^{2}+n \sigma_{\mathrm{T} \times \mathrm{S}(I)}^{2}+a n \sigma_{\mathrm{S}(I)}^{2}$ \\
\hline${ }^{9} \mathrm{~S}(C s)$ & $(b-1)(c-1)$ & $\sigma_{\mathrm{e}-C s}^{2}+n \sigma_{\mathrm{T} \times \mathrm{S}(C s)}^{2}+a n \sigma_{\mathrm{S}(C S)}^{2}$ \\
\hline${ }^{\mathrm{f}} \mathrm{T} \times \mathrm{L}$ & $(a-1)(b-1)$ & $\sigma_{\mathrm{e}}^{2}+n \sigma_{\mathrm{T} \times \mathrm{S}(\mathrm{L})}^{2}+c n \sigma_{\mathrm{T} \times \mathrm{L}}^{2}$ \\
\hline${ }^{\mathrm{e}} \mathrm{T} \times I-\mathrm{V}-\mathrm{Cs}$ & $(a-1)$ & $\sigma_{\mathrm{e}-I}^{2}+n \sigma_{\mathrm{T} \times \mathrm{S}(I)}^{2}+c n \sigma_{\mathrm{T} \times \mathrm{L}}^{2}+c n \sigma_{\mathrm{T} \times I-\mathrm{v}-\mathrm{Cs}}^{2}$ \\
\hline${ }^{\mathrm{d}} \mathrm{T} \times C s$ & $(a-1)(b-2)$ & $\sigma_{\mathrm{e}-C s}^{2}+n \sigma_{\mathrm{T} \times S(C s)}^{2}+c n \sigma_{\mathrm{T} \times C s}^{2}$ \\
\hline${ }^{\mathrm{c}} \mathrm{T} \times \mathrm{S}(\mathrm{L})$ & $(a-1) b(c-1)$ & $\sigma_{\mathrm{e}}^{2}+n \sigma_{\mathrm{T} \times \mathrm{S}(\mathrm{L})}^{2}$ \\
\hline${ }^{\mathrm{b}} \mathrm{T} \times \mathrm{S}(I)$ & $(a-1)(c-1)$ & $\sigma_{\mathrm{e}-I}^{2}+n \sigma_{\mathrm{T} \times \mathrm{S}(I)}^{2}$ \\
\hline${ }^{\mathrm{b}} \mathrm{T} \times \mathrm{S}(C s)$ & $(a-1)(b-1)(c-1)$ & $\sigma_{\mathrm{e}-C S}^{2}+n \sigma_{\mathrm{T} \times \mathrm{S}(C s)}^{2}$ \\
\hline Residual & $a b c(n-1)$ & $\sigma_{\mathrm{e}}^{2}$ \\
\hline${ }^{\mathrm{a}} \operatorname{Res} I$ & $a c(n-1)$ & $\sigma_{\mathrm{e}-I}^{2}$ \\
\hline${ }^{\text {a }} \operatorname{Res} C s$ & $a c(b-1)(n-1)$ & $\sigma_{\mathrm{e}-C s}^{2}$ \\
\hline Total & $a b c n-1$ & \\
\hline \multicolumn{3}{|c|}{$\begin{array}{l}{ }^{a} \text { A distinction is made between } \sigma_{\mathrm{e}-I}^{2} \text { and } \sigma_{\mathrm{e}-C S}^{2} \text { to emphasize that impacts may affect measures of spatial variance at the scale } \\
\text { of replicate quadrats. This proposition is tested using a bootstrapping procedure (similar tests were done to compare } \sigma^{2} \times \mathrm{S}(I) \\
\text { with } \sigma_{\mathrm{T} \times \mathrm{S}(C s)}^{2} \text { and } \sigma_{\mathrm{S}(I)}^{2} \text { with } \sigma_{\mathrm{S}(C s) \text {, see 'Materials and methods'). However, all the analyses on mean effects assume no differ- }}^{2} \sigma_{\mathrm{e}-I}^{2} \text { and } \sigma_{\mathrm{e}-C s_{1}}^{2} \text { so that both components estimate the common within-group variance } \sigma_{\mathrm{e}}^{2}\end{array}$} \\
\hline \multicolumn{3}{|c|}{$\begin{array}{l}{ }^{\mathrm{b}} \text { These tests are constructed using the natural denominator (i.e. Res } I \text { for } \mathrm{T} \times \mathrm{S}(I) \text { and Res } C s \text { for } \mathrm{T} \times \mathrm{S}(C S) \text { ), not the pooled one } \\
\text { (the overall residual) }\end{array}$} \\
\hline \multicolumn{3}{|c|}{${ }^{\mathrm{C}}$ Tested over the Residual term } \\
\hline \multicolumn{3}{|c|}{${ }^{\mathrm{d}}$ Tested over $\mathrm{T} \times \mathrm{S}(\mathrm{Cs})$} \\
\hline \multicolumn{3}{|c|}{$\begin{array}{l}\text { eTested over the Resid } \\
\text { 1991, Underwood } 19 \\
\text { assume equivalence }\end{array}$} \\
\hline \multicolumn{3}{|l|}{${ }^{\mathrm{f}}$ Tested over $\mathrm{T} \times \mathrm{S}(\mathrm{L})$} \\
\hline \multicolumn{3}{|c|}{${ }^{9}$ Tested over $\mathrm{T} \times \mathrm{S}(\mathrm{Cs})$} \\
\hline \multicolumn{3}{|l|}{${ }^{\mathrm{h}}$ Tested over $\mathrm{T} \times \mathrm{S}(I)$} \\
\hline \multicolumn{3}{|l|}{${ }^{\mathrm{i}}$ Tested over $\mathrm{T} \times \mathrm{S}(\mathrm{L})$} \\
\hline \multicolumn{3}{|c|}{$\begin{array}{l}{ }^{\mathrm{j}} \text { Tested over } \mathrm{T} \times C S \text { if } \mathrm{S}(C s) \text { can be eliminated; tested over } \mathrm{S}(C s) \text { if } \mathrm{T} \times C s \text { can be eliminated; tested over } \mathrm{T} \times \mathrm{S}(C s) \text { if both } \mathrm{T} \times \\
C s \text { and } \mathrm{S}(C s) \text { can be eliminated from the model }\end{array}$} \\
\hline \multicolumn{3}{|c|}{ 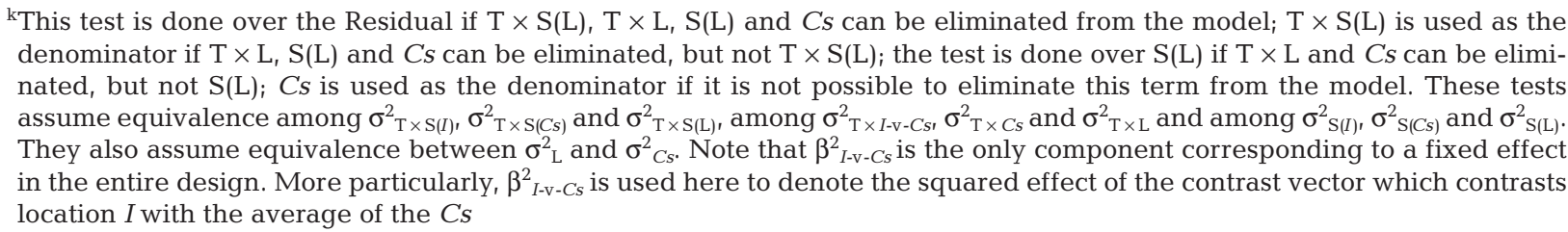 } \\
\hline
\end{tabular}

also obtained for the difference between the variance components for $I$ and $C s$ at the scale of residuals, at the scale of sites, and for the $\mathrm{T} \times \mathrm{S}(\mathrm{L})$ component, providing a basis for direct comparisons. Data for $I$ and $C s$ were bootstrapped separately. For estimating error variances, individual observations were sampled with replacement within each combination of Time $\times$ Site (Location), whereas for the other terms (i.e. Sites and Time $\times$ Site interactions), bootstrap data were obtained by sampling randomly and with replacement a Time and then a Site, keeping the individual observations within a cell together (Davison \& Hinkley 1997, p. 100-102). Variance components were estimated using REML estimators for each of 5000 bootstrap samples; bias-corrected confidence intervals were obtained using the 0.025 and 0.975 percentiles of the bootstrap distributions (Efron \& Tibshirani 1993, Manly 1997). Confidence intervals that did not include zero provided evidence of differences between I and Cs. All bootstrap confidence intervals were calculated using a special-purpose computer program (Bootvar.exe) written in FORTRAN by M.J.A. 
Cochran's C-test (Underwood 1997) was used to check the assumption of homogeneity of variances prior to testing hypotheses concerning mean differences. This was not a requirement for obtaining estimates of variance components. In some cases, data were $\ln (x+1)$-transformed to remove heterogeneous variances. When there was no suitable transformation, analyses were performed on untransformed data. ANOVA, in fact, is considered robust to departures from the assumption of homogeneous variances, particularly with balanced designs and when there are many independent estimates of sample variance. ANOVAs were performed using GMAV 5 software (University of Sydney, Australia).

Multivariate analyses. Distance-based premutational multivariable analysis of variance (PERMANOVA, Anderson 2001a) was used to analyze the multivariate assemblage data for the full multi-factor design, including all contrasts and partitions involving impact and control locations. This was achieved by explicitly treating ANOVA as a linear model in a distance-based redundancy analysis (McArdle \& Anderson 2001). Each term in the analysis was coded as a design matrix and tested individually with the appropriate denominator and relevant permutable units using the computer program DISTLM.exe (Anderson 2004). The analyses tested the same hypotheses described above for univariate data but in a multivariate context. All multivariate analyses were based on Bray-Curtis dissimilarities (Bray \& Curtis 1957) on untransformed data (58 taxa) and each term in the analysis was tested using 4999 random permutations of the appropriate units (Anderson 2001b, Anderson \& ter Braak 2003). For example, a test of the term $\mathrm{T} \times \mathrm{L}$ requires permutation of cells corresponding to the 48 $\mathrm{T} \times \mathrm{S}(\mathrm{L})$ units (i.e. keeping observations within cells together as a unit, see 'Results'). For some terms in the analysis, there were not enough permutable units to get a reasonable test by permutation, so a p-value was obtained using a Monte Carlo random sample from the asymptotic permutation distribution (Anderson \& Robinson 2003, see Eq. 4 therein).

To visualize multivariate patterns, non-metric multidimensional scaling (nMDS) ordinations were done (Kruskal \& Wish 1978) on the basis of a Bray-Curtis dissimilarity matrix calculated from untransformed data. As there were too many observation points to view in a single ordination, we examined centroids of the $48 \mathrm{~T} \times$ $\mathrm{S}(\mathrm{L})$ cells. We also examined centroids of the $16 \mathrm{~T} \times \mathrm{L}$ cells. The centroids in multivariate space defined by the Bray-Curtis measure are not the same as the arithmetic averages of the original variables (Anderson 2001a). Thus, to obtain the plots, we calculated principal coordinates (Gower 1966) from the full Bray-Curtis dissimilarity matrix among all pairs of the 480 observa- tions. This places the observations into a Euclidean framework, but preserves the Bray-Curtis measure: that is, the Euclidean distance between any pair of observations using these principal coordinates is equivalent to the Bray-Curtis dissimilarity between those 2 points using the original variables. Centroids, as arithmetic averages, were therefore calculated using these principal coordinates. The Euclidean distance between each pair of centroids was then calculated and used as the input distance matrix for the nMDS algorithm.

In light of the precautionary principle (Gray 1990, Fairweather 1991) and the relatively small number of degrees of freedom for some of the tests, we decided to use an a priori significance level of $\alpha=0.10$ as a decision criterion for interpreting statistical results in both multivariate and univariate analyses.

The SIMPER procedure (Clarke 1993) was used to identify, at each time of sampling, the percentage contribution $\left(\bar{\delta}_{i} \%\right)$ that each species (or taxon) made to the measures of the Bray-Curtis dissimilarity $\left(\bar{\delta}_{i}\right)$ between the average of the $C s$ versus $I$. This analysis allowed identification of the species (or taxa) that were most important in differentiating $I$ from the Cs. Species (or taxa) were selected as 'important' if they exceeded an arbitrarily chosen threshold value of percent dissimilarity $\geq 3 \%$.

The average contribution $\bar{\delta}_{1}$ of individual taxa to the dissimilarity between 2 groups ( $I$ vs $C s$, in our case) is calculated between all pairs of inter-group samples. This value $\left(\bar{\delta}_{i}\right)$ can either suggest a consistent indicator taxon or not, depending on how often the taxon contributed to the inter-comparison of all samples in the 2 groups (Clarke 1993). The ratio $\bar{\delta}_{i} / \mathrm{SD}\left(\delta_{i}\right)$ was, therefore, also calculated for each species/taxon identified as 'important' by SIMPER. A large value of $\bar{\delta}_{i} / \mathrm{SD}\left(\delta_{i}\right)$ (i.e. exceeding 1 ) indicated that the contribution of the given taxon to the average dissimilarity $\bar{\delta}_{i}$ was relatively consistent across the majority of samples in the comparison of $I$ versus Cs.

\section{RESULTS}

\section{Multivariate analyses}

Multivariate analyses provided evidence for statistically significant impacts of the outfall on multivariate assemblages (Table 2, Fig. 2). There was a significant $\mathrm{T} \times I$-v-Cs interaction term for the multivariate data (at $\alpha=0.1$, Table 1), indicating that the variation through time at the impact location differed significantly from the temporal changes that occurred, on average, at the control locations. This was also evident in the nMDS plot of the $\mathrm{T} \times \mathrm{L}$ centroids (Fig. 2a), where the direction of change through time was different for 
Table 2. PERMANOVA based on the Bray-Curtis dissimilarities (no transformation) of the multivariate data (58 taxa). Each test was done using 4999 permutations. p-values given in italics were obtained using 4999 Monte Carlo samples from the asymptotic permutation distribution. The term used for the denominator mean square in each case is given in the column $\mathrm{MS}_{\mathrm{denom}}$. Terms already involved in significant higher-order interactions were not analyzed

\begin{tabular}{|c|c|c|c|c|c|c|c|}
\hline Source of variation & $\mathrm{df}$ & SS & MS & $F$ & $\mathrm{p}$ & $\mathrm{MS}_{\mathrm{denom}}$ & Permutable units \\
\hline Time $=\mathrm{T}$ & 3 & 55428.79 & 18476.26 & & & & \\
\hline Location = L & 3 & 262508.49 & 87502.83 & & & & \\
\hline$I-\mathrm{v}-C s$ & 1 & 157753.90 & 157753.90 & & & & \\
\hline Cs & 2 & 104754.58 & 52377.29 & & & & \\
\hline Site $(\mathrm{L})=\mathrm{S}(\mathrm{L})$ & 8 & 66754.37 & 8344.30 & & & & \\
\hline $\mathrm{S}(I)$ & 2 & 31621.70 & 15810.85 & & & & \\
\hline $\mathrm{S}(C s)$ & 6 & 35132.67 & 5855.45 & & & & \\
\hline $\mathrm{T} \times \mathrm{L}$ & 9 & 68405.96 & 7600.66 & & & & \\
\hline $\mathrm{T} \times I-\mathrm{v}-C s$ & 3 & 34140.45 & 11380.15 & 1.4 & 0.0760 & $\mathrm{~T} \times \mathrm{S}(\mathrm{L})$ & $48 \mathrm{~T} \times \mathrm{S}(\mathrm{L})$ cells \\
\hline $\mathrm{T} \times C s$ & 6 & 34265.51 & 5710.92 & 0.7 & 0.9276 & $\mathrm{~T} \times \mathrm{S}(C s)$ & $36 \mathrm{~T} \times \mathrm{S}(C s)$ cells \\
\hline $\mathrm{T} \times \mathrm{S}(\mathrm{L})$ & 24 & 189754.88 & 7906.45 & 5.8 & 0.0002 & Residual & 480 raw data units \\
\hline $\mathrm{T} \times \mathrm{S}(I)$ & 6 & 33554.73 & 5592.46 & 3.5 & 0.0002 & Res I & 120 raw data units \\
\hline $\mathrm{T} \times \mathrm{S}(C s)$ & 18 & 156200.15 & 8677.79 & 6.7 & 0.0002 & Res Cs & 360 raw data units \\
\hline Residual & 432 & 590008.31 & 1365.76 & & & & \\
\hline $\operatorname{Res} I$ & 108 & 171169.26 & 1584.90 & & & & \\
\hline Res Cs & 324 & 418839.04 & 1292.71 & & & & \\
\hline Total & 479 & 1232860.78 & & & & & \\
\hline
\end{tabular}

the impact location compared to the controls. In addition, small-scale temporal and spatial variability was evident, as there was significant multivariate variability through time from site to site at the impact and at the control locations (i.e. significant $\mathrm{T} \times \mathrm{S}[I]$ and $\mathrm{T} \times$ $\mathrm{S}[\mathrm{Cs}]$ terms in Table 2).

The presence of a significant $\mathrm{T} \times I-\mathrm{v}-\mathrm{Cs}$ interaction indicated that the difference between assemblages at $I$ versus those at $C$ s differed at different times. A change in the difference between $I$ and $C s$ could be due to a difference in either the direction of the multivariate effect or its size at different times. Separate PERMANOVAs were done, investigating the full spatial design separately at each time (Table 3 ). These analyses showed that the site-to-site variability within locations remained highly significant at all times of sampling $(\mathrm{p}<0.001)$ and that control locations differed significantly from one another for Times 1, 2 and $3(\mathrm{p}<$ 0.03), but not for Time 4 ( $p>0.20$, Table 3). Of greatest interest was the $I-\mathrm{v}-C s$ contrast, which was statistically significant at each of Times 1, 3 and $4(p<0.07)$, but not at Time 2 ( $p>0.13)$.

The average Bray-Curtis dissimilarity between assemblages at the impact location and those at any of the control locations was larger than that between assemblages from different control locations at all times except Time 2 (Table 3 ). At Time 2, the average dissimilarity between assemblages at Control Location 2 and the impact location was smaller than that between Control Locations 1 and 3. Thus, the lack of a significant $I$-v-Cs contrast at Time 2 was apparently due to greater among-control variation, causing a significant $\mathrm{T} \times I$-v-Cs interaction.
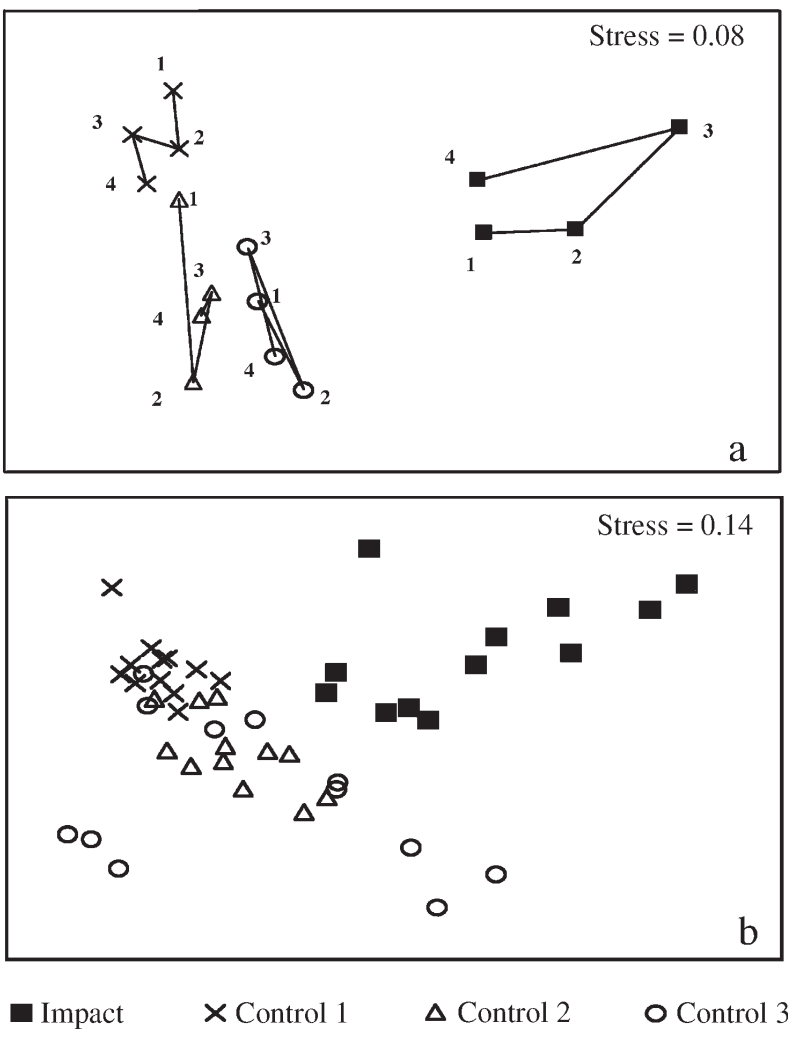

Fig. 2. Non-metric multidimensional scaling ordinations (nMDS plots) on the basis of the Bray-Curtis dissimilarity measure of (a) centroids of each location at each time of sampling, with the time sequence given as numbers on the plot and (b) centroids of the $\mathrm{n}=10$ observations for each site at each time of sampling. Centroids were calculated using principal coordinates (see text for further details) 
Table 3. Separate PERMANOVA analyses investigating the difference between impact versus control locations separately at each time based on the Bray-Curtis dissimilarity for 58 taxa. Each test was done using 4999 permutations of appropriate units, as shown. p-values given in italics were obtained using 4999 Monte Carlo samples from the asymptotic permutation distribution. The term used for the denominator mean square in each case is given in column $\mathrm{MS}_{\text {denom. }}$. Also given separately for each time are the average Bray-Curtis dissimilarities between assemblages from different locations

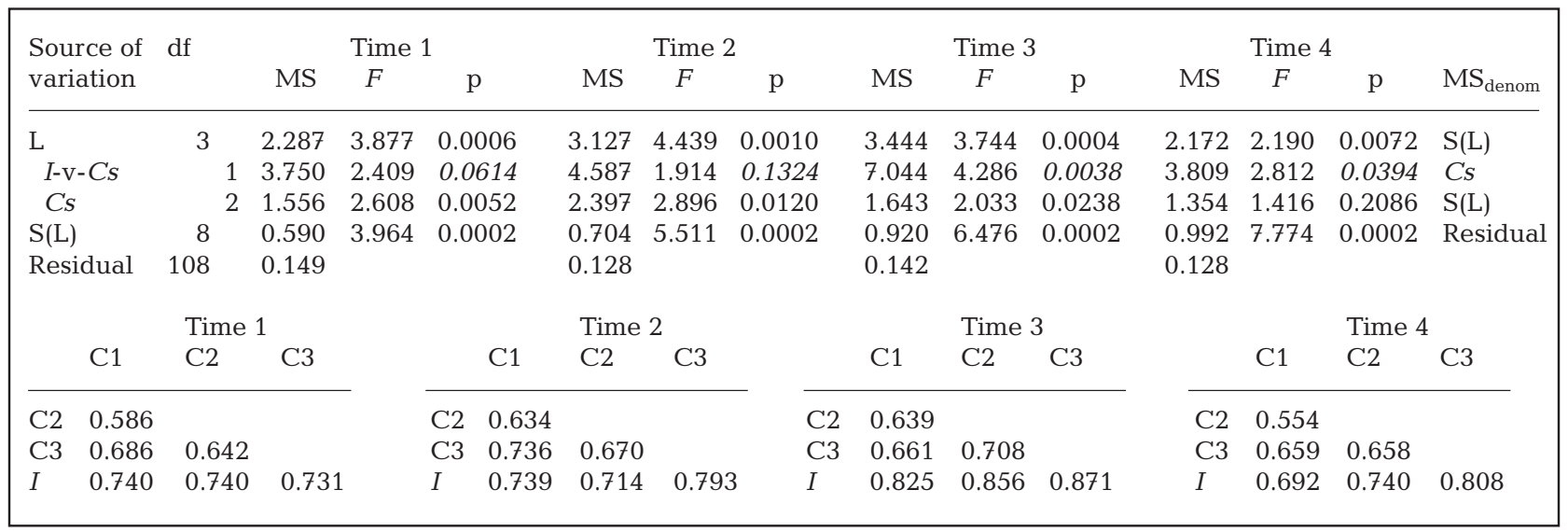

Patterns on the nMDS plots (Fig. 2) suggested that, although the magnitude of the difference between the impact and control locations might differ at different times of sampling (as confirmed by the separate analyses shown in Table 3), there may nevertheless be consistency in the direction of this difference. By this, we mean that the assemblage composition at the impact site, although temporally variable, may still be characterizably distinct from the controls. That is, the symbols corresponding to the impact location were all located in the upper right diagonal of the diagram, while the symbols corresponding to control locations were cleanly separated from these and located in the lower left diagonal, regardless of the time of sampling (Fig. 2b).

There were 14 taxa identified by SIMPER as being important in differentiating assemblages located at Cs from those at $I$, at each time of sampling (Table 4). Red algae of the family of Gelidiaceae (grouping Pterocladiella sp. and Gelidium sp.) were present almost exclusively at $I$ and made a strong contribution towards differences between $C s$ and $I$, at all times of sampling. The brown alga Colpomenia sinuosa was also exclusively present at $I$. However, due to its low abundance, its percentage contribution to the dissimilarity between $C s$ and $I$ reached the threshold value of $3 \%$ only at the first time of sampling. Encrusting calcified red algae and the encrusting sponge Crambe crambe also made important contributions to discriminate between $C_{s}$ and $I$ at all sampling occasions. Among algae, Dictyota dichotoma, Amphiroa spp., Padina pavonica, Corallina elongata and the groups of filamentous brown and green algae, were also important in differentiating between $C s$ and $I$. The relative contribution of these taxa, however, changed from time to time. The same pattern was recorded for the sponges of the family of Clionidae and the species Chondrosia reniformis and Chondrilla nucula, the boring bivalve Gastrochaena dubia and calcareous tubeworms of the family of Serpulidae (Table 4).

\section{Univariate analyses}

The analysis on mean number of taxa revealed significant differences among $C s$ and a significant $\mathrm{T} \times$ $\mathrm{S}(\mathrm{L})$ interaction, indicating large temporal and spatial variation in the response variable unrelated to the presence of the outfall (Table 5, Fig. 3a). The analysis on variance components revealed large differences between $I$ and $C s$, with larger variability among replicate quadrats at the disturbed location (Table 6). This analysis indicated that Res $I$ and Res Cs were not equivalent, suggesting that further tests of differences among means should be interpreted with caution (see Table 1).

Comparisons of variance components for encrusting calcified red algae indicated no significant difference between $I$ and $C s$ in measures of spatial variance at the scale of replicate quadrats and of sites, nor for the interaction between Time and Site (Table 6). There was also no evidence of impact on the mean cover of these algae (Table 5, Fig. 3b). Significant differences occurred among $C s$, highlighting large natural variability at this spatial scale (Table 5). There was also evidence of temporal changes in mean abundance that varied across sites (significant $\mathrm{T} \times \mathrm{S}[\mathrm{L}]$ interaction in Table 5).

The analysis on variance components for filamentous brown algae indicated no difference between $I$ and $C S$ in any of the comparisons (Table 6). In contrast, mean 
Table 4. Breakdown of average Bray-Curtis dissimilarity (untransformed data) values between Cs and $I$ into contributions from the most important taxa $\left(\bar{\delta}_{i}\right)$. At each of the 4 times of sampling, values exceeding an arbitrarily chosen threshold value of $\geq 3 \%$ are in bold. High values of the ratio $\bar{\delta}_{i} / \mathrm{SD}\left(\delta_{i}\right)$ (indicated by asterisks) denote that the contribution of the species (or taxon) to the dissimilarity between $C s$ and $I$ is reasonably consistent across all pairs of samples in the 2 groups

\begin{tabular}{|c|c|c|c|c|c|c|c|c|c|c|c|c|c|c|c|c|c|c|c|c|}
\hline \multirow[t]{2}{*}{ Taxon } & \multicolumn{5}{|c|}{$\begin{array}{c}\text { Time } 1 \\
\text { Average abundance }\end{array}$} & \multicolumn{5}{|c|}{$\begin{array}{c}\text { Time } 2 \\
\text { Average abundance }\end{array}$} & \multicolumn{5}{|c|}{$\begin{array}{c}\text { Time } 3 \\
\text { Average abundance }\end{array}$} & \multicolumn{5}{|c|}{$\begin{array}{c}\text { Time } 4 \\
\text { Average abundance }\end{array}$} \\
\hline & Cs & $I$ & $\bar{\delta}_{i}$ & $\bar{\delta}_{i} \%$ & $\frac{\bar{\delta}_{i}}{\operatorname{SD}\left(\delta_{i}\right)}$ & Cs & $I$ & $\bar{\delta}_{i}$ & $\bar{\delta}_{i} \%$ & $\frac{\bar{\delta}_{i}}{\operatorname{SD}\left(\delta_{i}\right)}$ & Cs & $I$ & $\bar{\delta}_{i}$ & $\bar{\delta}_{i} \%$ & $\frac{\bar{\delta}_{i}}{\operatorname{SD}\left(\delta_{i}\right)}$ & Cs & $I$ & $\delta_{i}$ & $\bar{\delta}_{i} \% \overline{\mathrm{S}}$ & $\frac{\bar{\delta}_{i}}{\operatorname{SD}\left(\delta_{i}\right)}$ \\
\hline Gelidiaceae & 0.0 & 17.1 & 13.3 & 17.8 & $1.0^{*}$ & 0.1 & 27.4 & 22.7 & 30.2 & $1.3^{*}$ & 0.0 & 19.2 & 17.9 & 21.2 & $1.5^{*}$ & 0.0 & 19.1 & 15.9 & 21.3 & 0.9 \\
\hline $\begin{array}{l}\text { Encrusting } \\
\text { calcified } \\
\text { red algae }\end{array}$ & 20.0 & 13.3 & 9.4 & 12.6 & $1.3^{*}$ & 13.3 & 9.7 & 7.4 & 9.8 & $1.2^{*}$ & 14.6 & 7.0 & 9.8 & 11.6 & $1.4^{*}$ & 12.2 & 15.4 & 10.4 & 13.9 & $1.3^{*}$ \\
\hline $\begin{array}{l}\text { Filamentous } \\
\text { brown algae }\end{array}$ & 3.5 & 11.5 & 9.1 & 12.2 & $1.1^{*}$ & 9.2 & 5.8 & 7.3 & 9.7 & $1.0^{*}$ & 2.6 & 0.0 & 2.4 & 2.9 & 0.7 & 4.4 & 3.2 & 3.5 & 4.7 & $1.0^{*}$ \\
\hline Clionidae & 7.5 & 0.9 & 4.4 & 5.9 & 0.5 & 4.6 & 3.1 & 3.4 & 4.5 & $1.1^{*}$ & 2.0 & 1.2 & 2.1 & 2.5 & 0.9 & 2.6 & 1.5 & 2.2 & 2.9 & $1.4^{*}$ \\
\hline $\begin{array}{l}\text { Chondrosia } \\
\text { reniformis }\end{array}$ & 1.2 & 4.7 & 4.1 & 5.5 & 0.6 & 0.6 & 3.7 & 3.3 & 4.4 & 0.4 & 0.3 & 0.0 & 0.3 & 0.4 & 0.3 & 0.3 & 2.8 & 2.4 & 3.2 & 0.5 \\
\hline $\begin{array}{l}\text { Filamentous } \\
\text { green algae }\end{array}$ & 4.7 & 1.5 & 3.9 & 5.2 & 0.8 & 2.9 & 0.2 & 2.4 & 3.2 & 0.7 & 1.7 & 1.7 & 2.3 & 2.8 & 0.8 & 2.5 & 1.2 & 2.3 & 3.0 & $1.0^{*}$ \\
\hline Crambe crambe & 2.8 & 2.5 & 3.4 & 4.6 & 0.6 & 2.4 & 1.8 & 2.8 & 3.8 & 0.7 & 3.7 & 1.2 & 3.8 & 4.5 & 0.7 & 2.5 & 1.1 & 2.6 & 3.5 & 0.7 \\
\hline $\begin{array}{l}\text { Dictyota } \\
\text { dichotoma }\end{array}$ & 1.9 & 3.0 & 3.4 & 4.6 & 0.5 & 1.6 & 0.2 & 1.3 & 1.7 & 0.4 & 0.9 & 1.9 & 2.2 & 2.6 & 0.8 & 1.3 & 1.5 & 1.7 & 2.3 & 0.8 \\
\hline $\begin{array}{l}\text { Colpomenia } \\
\text { sinuosa }\end{array}$ & 0.0 & 2.8 & 2.4 & 3.2 & 0.5 & 0.0 & 1.2 & 1.0 & 1.3 & 0.3 & 0.0 & 1.3 & 1.3 & 1.5 & 0.4 & 0.0 & 0.1 & 0.1 & 0.1 & 0.2 \\
\hline Serpulidae & 0.5 & 2.1 & 1.7 & 2.3 & 0.7 & 0.4 & 1.0 & 0.9 & 1.2 & 0.9 & 0.7 & 3.1 & 3.0 & 3.6 & 0.7 & 1.2 & 1.7 & 1.5 & 2.0 & $1.0^{*}$ \\
\hline $\begin{array}{l}\text { Gastrochaena } \\
\text { dubia }\end{array}$ & 0.1 & 1.7 & 1.4 & 1.9 & 0.7 & 0.0 & 0.3 & 0.3 & 0.4 & 0.3 & 0.0 & 7.2 & 6.9 & 8.2 & 0.6 & 0.1 & 1.1 & 1.0 & 1.5 & 0.6 \\
\hline Amphiroa sp. & 1.3 & 0.0 & 1.0 & 1.4 & 0.4 & 1.2 & 0.3 & 1.1 & 1.5 & 0.6 & 1.5 & 0.5 & 1.5 & 1.8 & 0.7 & 2.2 & 2.5 & 3.4 & 4.6 & 0.7 \\
\hline
\end{tabular}

Table 5. Summary of asymmetrical ANOVA on mean number of taxa, and on percentage cover of widespread and abundant taxa. Terms already involved in significant higher-order interactions were not analyzed. ${ }^{*} \mathrm{p}<0.1,{ }^{* *} \mathrm{p}<0.01,{ }^{* * *} \mathrm{p}<0.001$

\begin{tabular}{|c|c|c|c|c|c|c|c|c|c|c|c|c|c|}
\hline \multirow[t]{2}{*}{$\begin{array}{l}\text { Source of } \\
\text { variation }\end{array}$} & \multirow[t]{2}{*}{$\mathrm{df}$} & \multicolumn{2}{|c|}{$\begin{array}{l}\text { Mean no. } \\
\text { of taxa }\end{array}$} & \multicolumn{2}{|c|}{$\begin{array}{l}\text { Encrusting } \\
\text { calcified } \\
\text { red algae }\end{array}$} & \multicolumn{2}{|c|}{$\begin{array}{l}\text { Filamentous } \\
\text { brown algae }\end{array}$} & \multicolumn{2}{|c|}{$\begin{array}{l}\text { Filamentous } \\
\text { green algae }\end{array}$} & \multicolumn{2}{|c|}{$\begin{array}{l}\text { Encrusting } \\
\text { sponges }\end{array}$} & \multicolumn{2}{|c|}{$\begin{array}{l}\text { Encrusting } \\
\text { bryozoans }\end{array}$} \\
\hline & & MS & $F$ & MS & $F$ & MS & $F$ & MS & $F$ & MS & $F$ & MS & $F$ \\
\hline Time $=\mathrm{T}$ & 3 & 1.30 & & 5.19 & & 23.31 & & 198.67 & & 32.22 & & 18.52 & \\
\hline Location = L & 3 & 1.85 & & 25.21 & & 13.06 & & 104.35 & & 377.51 & & 109.30 & \\
\hline$I-\mathrm{v}-C s$ & 1 & 0.00 & 0.0 & 19.92 & 0.7 & 0.87 & & 279.13 & 3.2 & 93.01 & 0.2 & 84.10 & 0.7 \\
\hline Cs & 2 & 2.78 & $14.1^{* * *}$ & 27.92 & $16.1^{* * *}$ & 19.16 & $3.4^{*}$ & 16.96 & 0.5 & 519.76 & 5.0 & 121.90 & $15.3^{* * *}$ \\
\hline Site $(L)=S(L)$ & 8 & 0.11 & & 2.40 & & 3.41 & & 88.48 & & 89.68 & & 5.44 & \\
\hline $\mathrm{S}(I)$ & 2 & 0.17 & 1.3 & 8.21 & & 7.67 & & 1.50 & 4.4 & 44.34 & $8.8^{*}$ & 0.71 & \\
\hline $\mathrm{S}(C s)$ & 6 & 0.09 & & 0.46 & & 1.99 & & 117.47 & & 104.80 & & 7.02 & \\
\hline $\mathrm{T} \times \mathrm{L}$ & 9 & 0.09 & 0.5 & 1.52 & 0.8 & 9.80 & $2.2^{*}$ & 35.36 & 0.6 & 45.62 & 0.9 & 9.93 & 1.6 \\
\hline $\mathrm{T} \times I-\mathrm{v}-C S$ & 3 & 0.13 & 0.7 & 3.35 & 1.8 & 17.04 & $3.8^{*}$ & 32.00 & 0.5 & 18.62 & 0.4 & 17.61 & 2.9 \\
\hline $\mathrm{T} \times C s$ & 6 & 0.07 & 0.4 & 0.61 & 0.4 & 6.17 & 1.1 & 37.04 & 0.5 & 59.12 & 0.8 & 9.77 & 1.2 \\
\hline $\mathrm{T} \times \mathrm{S}(\mathrm{L})$ & 24 & 0.18 & $2.7^{* * *}$ & 1.83 & $4.6^{* * *}$ & 4.54 & $8.9^{* * *}$ & 61.11 & $4.5^{* * *}$ & 53.74 & $2.5^{* * *}$ & 6.09 & $1.8^{* * *}$ \\
\hline $\mathrm{T} \times \mathrm{S}(I)$ & 6 & 0.13 & 1.2 & 2.12 & $2.6^{*}$ & 1.24 & $2.7^{* *}$ & 0.34 & 0.2 & 5.06 & 0.4 & 0.46 & $3.8^{* * *}$ \\
\hline $\mathrm{T} \times \mathrm{S}(C s)$ & 18 & 0.20 & $3.7^{* * *}$ & 1.73 & $6.8^{* * *}$ & 5.64 & $10.7^{* * *}$ & 81.36 & $4.7^{* * *}$ & 69.97 & $2.8^{* * *}$ & 7.97 & $1.8^{*}$ \\
\hline Residual & 432 & 0.07 & & 0.40 & & 0.51 & & 13.63 & & 21.85 & & 3.30 & \\
\hline $\operatorname{Res} I$ & 108 & 0.11 & & 0.81 & & 0.47 & & 1.98 & & 12.32 & & 0.12 & \\
\hline Res Cs & 324 & 0.05 & & 0.26 & & 0.53 & & 17.51 & & 25.02 & & 4.36 & \\
\hline Cochran test & & $\begin{array}{l}C= \\
\mathrm{p}>\end{array}$ & $\begin{array}{l}0.07 \\
0.05\end{array}$ & $\begin{array}{l}C=( \\
\mathrm{p}>\end{array}$ & $\begin{array}{l}0.07 \\
0.05\end{array}$ & $\begin{array}{l}C= \\
\mathrm{p}>\end{array}$ & $\begin{array}{l}0.07 \\
0.05\end{array}$ & $\begin{array}{l}C=0 \\
\mathrm{p}<0\end{array}$ & $\begin{array}{l}.18, \\
.01\end{array}$ & & $\begin{array}{l}C=0.17 \\
\mathrm{p}<0.01\end{array}$ & $\begin{array}{l}C=0 \\
\mathrm{p}<\end{array}$ & $\begin{array}{l}0.21 \\
0.01\end{array}$ \\
\hline Transformatio & & $\ln (x$ & $+1)$ & $\ln (x$ & $+1)$ & $\ln (x$ & $+1)$ & Nor & & & None & No & ne \\
\hline
\end{tabular}



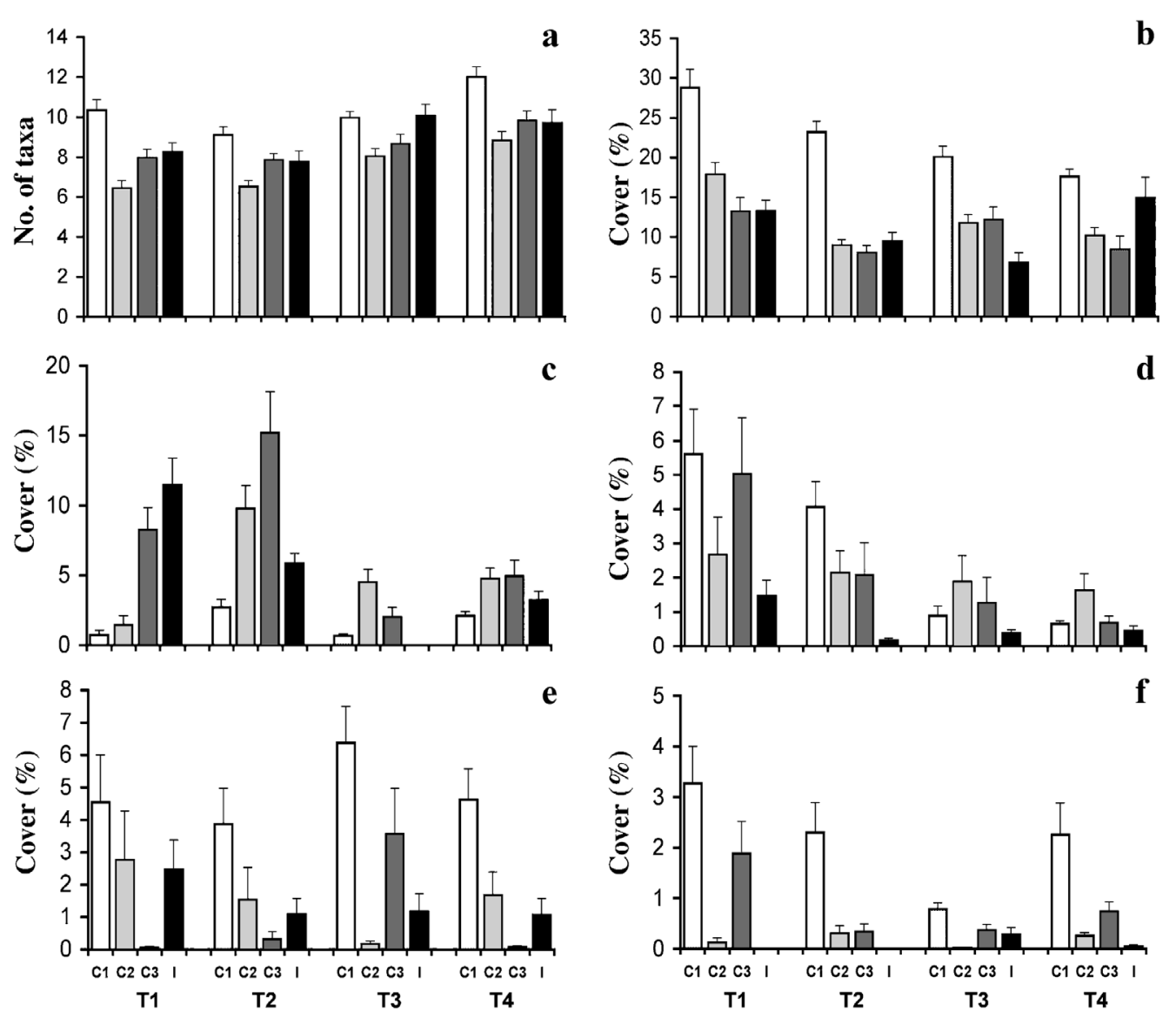

Fig. 3. Mean $( \pm \mathrm{SE}, \mathrm{n}=30)$ total number of taxa (a) and \% cover for widespread and abundant taxa at I and Cs (C1, C2 and C3) at each of the 4 sampling times (T1, T2, T3, T4); (b) encrusting calcified red algae; (c) filamentous brown algae; (d) filamentous green algae; (e) encrusting sponges; (f) encrusting bryozoans

percentage cover differed between $I$ and $C s$ inconsistently with time, providing evidence in support of an effect of the outfall ( $\mathrm{T} \times I$-v-Cs is significant in Table 5). This pattern was largely driven by the disappearance of these algae at $I$ at Time 3 (Fig. 3c). Time by Site interactions were significant at $C s$ and at $I$ (Table 5).

Comparisons of variance components for filamentous green algae revealed significantly more variation at $C s$ than at $I$ in terms of spatial heterogeneity at the scale of quadrats and as temporal variability in amongsite differences (Table 6). Although these patterns indicate that analyses on mean values should be viewed with caution, there was greater average cover of filamentous green algae at Cs compared to $I$ (Fig. 3d).

Temporal changes in among-site differences were larger at $C$ s compared to $I$ for encrusting sponges, as indicated by the analysis on variance components (Table 6). In contrast, there was no evidence for any differences between $I$ and $C s$ in mean cover of these animals (Fig. 3e, Table 5).

Encrusting bryozoans were much more variable at the scale of replicate quadrats at Cs compared to $I$, as indicated by the comparison of variance components (Table 6). These organisms were also more abundant on average at $C s$ compared to $I$ (Fig. 3f). Time by Site interactions were significant at $C s$ and at $I$ (Table 5) and there was also significantly greater Time by Site variability at $C s$ compared to $I$ (Table 6).

\section{DISCUSSION}

This study detected significant differences between assemblages at a location exposed to sewage and those at control locations. Multivariate analyses indicated that differences between $I$ and $C S$ were significantly greater than the variation among control locations in 3 out of the 4 times sampled. In addition, the direction of the difference (i.e. the specific taxa that characterized differences) was similar at all times.

Several taxa characterized the differences found between disturbed and control locations, with some algae (e.g. Colpomenia sinuosa, Gelidium sp. and Pterocladiella sp.) occurring uniquely at the disturbed 
Table 6. REML estimators of variance components and bootstrap differences between disturbed and reference locations [Res- $I-$ Res-Cs, $\mathrm{T} \times \mathrm{S}(I)-\mathrm{T} \times \mathrm{S}(C s)$ and $\mathrm{S}(I)-\mathrm{S}(C s)]$. CI(low) and $\mathrm{CI}($ high) are the 0.025 and 0.975 percentiles of the bootstrap distributions of the differences, respectively. Mean differences in variance components that were significantly different from zero ( $\alpha=0.05)$ are indicated with an asterisk. Differences at the scale of site were not examined if $\mathrm{T} \times \mathrm{S}(I)$ and $\mathrm{T} \times \mathrm{S}(\mathrm{Cs})$ already differed significantly

\begin{tabular}{|c|c|c|c|c|c|}
\hline Response variable & Source of variation & Variance component & Mean difference & CI(low) & CI(high) \\
\hline No. of taxa & $\begin{array}{l}\text { Res } I \\
\operatorname{Res} C S \\
\mathrm{~T} \times \mathrm{S}(I) \\
\mathrm{T} \times \mathrm{S}(C s) \\
\mathrm{S}(I) \\
\mathrm{S}(C s)\end{array}$ & $\begin{array}{l}9.4407 \\
4.6469 \\
0.2034 \\
1.0139 \\
0.0000 \\
0.0000\end{array}$ & $\begin{array}{c}4.3068^{*} \\
-0.6947 \\
0.0040\end{array}$ & $\begin{array}{r}2.6808 \\
-2.1893 \\
-0.5472\end{array}$ & $\begin{array}{l}6.9167 \\
0.7456 \\
0.6000\end{array}$ \\
\hline $\begin{array}{l}\text { Encrusting calcified } \\
\text { red algae }\end{array}$ & $\begin{array}{l}\text { Res } I \\
\operatorname{Res} C s \\
\mathrm{~T} \times \mathrm{S}(I) \\
\mathrm{T} \times \mathrm{S}(C s) \\
\mathrm{S}(I) \\
\mathrm{S}(C s)\end{array}$ & $\begin{array}{r}70.2468 \\
50.1728 \\
15.6545 \\
17.2066 \\
7.2504 \\
0.0000\end{array}$ & $\begin{array}{r}17.9842 \\
3.0536 \\
-0.0191\end{array}$ & $\begin{array}{c}-2.0427 \\
-29.8014 \\
-5.45610\end{array}$ & $\begin{array}{l}46.2070 \\
43.5116 \\
20.9919\end{array}$ \\
\hline $\begin{array}{l}\text { Filamentous } \\
\text { brown algae }\end{array}$ & $\begin{array}{l}\text { Res } I \\
\operatorname{Res} C S \\
\mathrm{~T} \times \mathrm{S}(I) \\
\mathrm{T} \times \mathrm{S}(C S) \\
\mathrm{S}(I) \\
\mathrm{S}(C s)\end{array}$ & $\begin{array}{r}28.0769 \\
24.4441 \\
4.9287 \\
30.0393 \\
4.6403 \\
0.0000\end{array}$ & $\begin{array}{r}3.3316 \\
-13.9132 \\
-0.0673\end{array}$ & $\begin{array}{r}-8.6279 \\
-73.8604 \\
-4.6684\end{array}$ & $\begin{array}{r}14.6559 \\
3.1437 \\
13.4638\end{array}$ \\
\hline $\begin{array}{l}\text { Filamentous } \\
\text { green algae }\end{array}$ & $\begin{array}{l}\text { Res } I \\
\text { Res } C S \\
\mathrm{~T} \times \mathrm{S}(I) \\
\mathrm{T} \times \mathrm{S}(C S)\end{array}$ & $\begin{array}{r}1.8849 \\
17.5131 \\
0.0000 \\
6.3852\end{array}$ & $\begin{array}{l}-13.9479^{*} \\
-4.3794^{*}\end{array}$ & $\begin{array}{l}-22.1365 \\
-16.4580\end{array}$ & $\begin{array}{l}-9.1910 \\
-1.5582\end{array}$ \\
\hline $\begin{array}{l}\text { Encrusting } \\
\text { sponges }\end{array}$ & $\begin{array}{l}\text { Res } I \\
\operatorname{Res} C S \\
\mathrm{~T} \times \mathrm{S}(I) \\
\mathrm{T} \times \mathrm{S}(C s)\end{array}$ & $\begin{array}{r}11.9374 \\
25.0218 \\
0.0000 \\
4.4947\end{array}$ & $\begin{array}{l}-10.3896 \\
-3.0151^{*}\end{array}$ & $\begin{array}{l}-24.7663 \\
-10.8957\end{array}$ & $\begin{array}{r}0.3464 \\
-0.5094\end{array}$ \\
\hline $\begin{array}{c}\text { Encrusting } \\
\text { bryozoans }\end{array}$ & $\begin{array}{l}\text { Res } I \\
\operatorname{Res} C S \\
\mathrm{~T} \times \mathrm{S}(I) \\
\mathrm{T} \times \mathrm{S}(C S) \\
\mathrm{S}(I) \\
\mathrm{S}(C S)\end{array}$ & $\begin{array}{l}0.1190 \\
4.3627 \\
0.0337 \\
0.3366 \\
0.0064 \\
0.0000\end{array}$ & $\begin{array}{l}-3.8172^{*} \\
-0.0604 \\
-0.0011\end{array}$ & $\begin{array}{l}-5.8486 \\
-0.8808 \\
-0.1935\end{array}$ & $\begin{array}{r}-2.7436 \\
0.1867 \\
0.1952\end{array}$ \\
\hline
\end{tabular}

location. Univariate analyses indicated a significant Time $\times I$-v-Cs interaction for filamentous brown algae, whereas a trend for an overall difference between $I$ and $C s$ was evident for filamentous green algae. The analysis on variance components indicated significantly larger spatial variation at the scale of quadrats at $I$ compared to $C s$ for number of taxa, whereas the opposite pattern occurred for filamentous green algae and bryozoans. In addition, Space $\times$ Time interactivity at the scale of sites was significantly larger at Cs compared to $I$ for filamentous green algae and encrusting sponges. In summary, ongoing differences between $I$ and $C s$ were, therefore, characterized by the location near the outfall $(I)$ having greater variation in the number of taxa at small spatial scales, accompanied by decreased abundance and variability of green filamentous algae, encrusting sponges and bryozoans compared to the control locations (Cs).

A common pattern in the data was the significant amount of variability among controls, a finding that confirms the importance of selecting multiple controls in designing experiments aimed at detecting ecological impacts of human activities (Underwood 1994, Glasby \& Underwood 1998). It is also worth noting that in a preliminary report on the effect of the same outfall (Terlizzi et al. 2002), lack of temporal replication prevented the detection of differences between $I$ and $C s$ for some of the analyzed variables. This stresses the importance of obtaining proper temporal replication before drawing inferences about potential impacts. Several findings from this study have a number of important implications for future multivariate and univariate analyses in the assessment of environmental impacts. 


\section{Multivariate analyses}

Clarke \& Green (1988) and Clarke (1993) provided a non-parametric multivariate permutation test for differences among a priori groups called analysis of similarities (ANOSIM). As evidenced by the context in which the test was presented, it has a special utility, more particularly, in the comparison of polluted versus control sites in environmental impact assessment (Clarke \& Green 1988, Warwick et al. 1990, Clarke 1993). The special strengths of this method are numerous. First, it is very flexible: it can be based on any dissimilarity measure relevant to the ecological problem and data at hand. Second, it is robust, as it does not rely on any particular assumptions regarding the distribution of original variables, unlike traditional multivariate test statistics. Third, it is truly non-parametric: as the test statistic is calculated from ranks of dissimilarities, it does not include estimation of any parameters from linear or non-linear models, and thus mirrors the robust utility of non-metric multi-dimensional scaling as an ordination method. Fourth, it is elegant, understandable, interpretable and easy to communicate because of its simplicity.

Despite these strengths, Clarke (1993) admits that 'many impact studies are not confined to 1-way layouts; some recommended designs mix both spatial and temporal components and have hierarchies of spatial sampling... these designs can become very complex... It is a major challenge to even begin to translate such structures into the present distribution-free multivariate context of the present paper, and one that could only ever be partially successful' ( $p$ 134).

It is clear that measures of patterns in whole assemblages of species can provide the most useful information for interpreting the consequences of pollution to an ecological system (Underwood \& Peterson 1988) and are also generally more sensitive to environmental changes than individual indicator species variables or other univariate indices, such as the Shannon diversity index (Clarke 1993). Although it would be appealing to simply use ANOSIM for tests of environmental impacts on multivariate assemblages, potential problems of erroneous statistical inferences obtained from using simple experimental designs for complex problems (e.g. due to the lack of measures of variation at appropriate spatial scales or pseudo replication, etc., see Stewart-Oaten et al. 1986 and Underwood 1991, 1992) must logically exist for multivariate tests, just as they do for univariate ones. This highlights the need for a multivariate similarity-based framework for testing hypotheses that can also accommodate complex experimental designs.

PERMANOVA (McArdle \& Anderson 2001, Anderson 2001a) provides a method whereby multivariate data can be analyzed in response to complex experimental designs. While numerous studies have used this method to examine general ecological hypotheses, this is its first direct use, to our knowledge, in the context of environmental impact assessment. In addition, the linear contrast of $I$ versus $C s$, so important in many beyond-BACI designs, could be tested explicitly for the multivariate data by setting up an appropriate test criterion (as articulated by McArdle \& Anderson 2001) and an appropriate permutation method (as articulated by Anderson \& ter Braak 2003). Furthermore, the fact that the asymptotic permutation distribution of these multivariate test statistics can be determined for any individual data set (see Anderson \& Robinson 2003 for details), means that one can obtain p-values for tests of hypotheses even when the possible number of permutations is too small to obtain a meaningful test.

Applying a complex linear model to a distance matrix does not come without some consequences, however. Of the 4 desirable qualities identified above for ANOSIM, PERMANOVA retains, at least, the first 2 of these. It retains the flexibility that any dissimilarity measure can be used. It is also a distribution-free method in that estimation and inference is based on a statistic whose distribution does not depend in any way on complete specification of the distributions of the species variables (Gibbons 1982, Noether 1985). One might argue, however, that it is 'semi-parametric' (rather than non-parametric) in the sense that the partitioning implicitly applies a linear model (thus, involving some parameterization) to the distances. Once chosen, the dissimilarity measure is essentially driving the analysis (there is no ranking of distances, as with ANOSIM) and so one must take special care to ensure that the measure chosen appropriately reflects changes in the structure of assemblages that are biologically and/or ecologically meaningful. The point is, PERMANOVA is non-parametric in the sense of being 'distribution-free', but it does not avoid all kinds of parameterization in the sense that it does specify a linear model on distances. We believe, however, that this is a reasonable thing to do provided the distance or dissimilarity measure reflects the properties of changes in the structure of assemblages that are of greatest interest to the researcher.

A further consequence of using the PERMANOVA approach is that it may be difficult to unravel or interpret the meaning of significant multivariate interaction terms. First of all, a dissimilarity measure between 2 assemblages is not a uniquely interpretable number in an ecological sense. For example, a Bray-Curtis dissimilarity of $60 \%$ between 2 observation units may mean a difference in relative abundances for certain taxa, while it may mean a difference in relative frequencies of taxa between 2 other observation units. 
Thus, a dissimilarity measure suffers from some of the same problems of 'non-uniqueness' as those observed for community measures of diversity or evenness (Clarke 1993). Multivariate dissimilarity measures do, however, take into account the identity of species in determining both size and direction of distances, which is a major distinction from other community indices. If a difference is found between assemblages, it should be interpretable in some way by reference to the chosen dissimilarity measure.

Interactions in multivariate data can be due to differences in the size or the direction of the effects of one factor across levels of another factor. With the PERMANOVA approach, these differences in size or direction are defined by the dissimilarity measure (and therefore the space) chosen for the analysis. This is similar to the interpretation of univariate interactions, with the important difference being that the directionality issue is multidimensional, rather than being simply an increase or a decrease along a single dimension.

To unravel and interpret the meaning of the significant multivariate interaction in the present study, it was necessary to examine: (1) the average values of the Bray-Curtis dissimilarity measure between impact and control assemblages and among controls at different times, to examine sizes of effects based on this measure; (2) patterns in the ordination diagram showing both factors, to visually evaluate possible differences in the size or direction of effects at different times and (3) results of SIMPER and other univariate analyses, to further characterize the nature of effects at each time in terms of the biota. Although not needed in the present investigation, other multivariate methods, including canonical techniques such as generalized discriminant analysis based on distances (Anderson \& Robinson 2003, Anderson \& Willis 2003), might also be used to advantage to investigate specific issues of differences in directionality among levels of factors. Such approaches may be particularly helpful when the reasons for a significant interaction are not readily visually apparent from unconstrained ordination plots, such as nMDS, or if such plots have high stress values, making them difficult to interpret.

The successful use of PERMANOVA in the analysis of multi-species responses to sewage in the present study bodes well for future monitoring and impact studies. The results obtained were clear, interpretable and were consistent with patterns seen in the multivariate ordination plots. In addition, simplification of complex spatio-temporal interactions using sums or averages, which can also introduce problems of pseudo-replication, did not need to be done in order to successfully analyze these multivariate data simultaneously using PERMANOVA. As a result, the poten- tial basis for statistical inferences and the spatial scale of effects using the full experimental design was not compromised, but remained intact, as for the analogous univariate analyses.

\section{Univariate analyses}

Univariate analyses indicated a general reduction in mean abundance of some organisms close to the outfall, either consistently (filamentous green algae) or inconsistently (filamentous brown algae) with time. Similarly, spatial patchiness at the scale of quadrat and temporal changes in among-site differences were generally reduced close to the outfall. These patterns reflected a positive correlation between the mean and the variance, which is a common feature of ecological variables such as density and cover of organisms (Taylor 1961, Hurlbert 1990). Effects on variances, however, could be detected more easily than effects on means in this study. This reinforced the view that careful studies of environmental impacts should consider potential effects on variances in addition to potential mean effects on populations, as suggested by other studies (Underwood 1991, Warwick \& Clarke 1993, Chapman et al. 1995).

Given the sensitivity of measures of spatial and temporal variance in abundance to anthropogenic disturbance, it is important that the tests based on these measures can unambiguously identify the nature of the impact and the scales over which impacts occur. Traditionally, 2-tailed $F$ ratios in beyond-BACI designs have been based on mean squares that are linear combination of variances (but see Bishop et al. 2002). For example, the mean square of the $\mathrm{T} \times \mathrm{S}(\mathrm{L})$ interaction is a linear combination that includes the variance among replicate quadrats and the variance due to the Time $x$

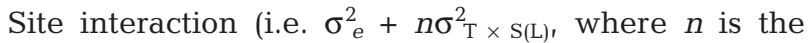
number of replicate quadrats). If there is homogeneity of variances, as tested by Cochran's $C$-test prior to ANOVA, a 2-tailed $F$ ratio based on the $\mathrm{T} \times \mathrm{S}(C s)$ and $\mathrm{T} \times \mathrm{S}(I)$ mean squares is a test of the null hypothesis that the Time $\times$ Site interaction does not differ between disturbed and control locations. Rejection of this hypothesis unambiguously identifies the Time $\times$ Site interaction as the component of the mean square potentially affected by disturbance, providing insights into the nature and scale of the impact.

In contrast, if there is heterogeneity of variances, as occurred for several taxa in this study, 1 or both components of the mean square of the $\mathrm{T} \times \mathrm{S}(\mathrm{L})$ interaction may contribute to a significant 2-tailed $F$ test. In this case, it is not possible to determine whether the impact occurs as a change in spatial variance among replicate units, as a change in the Time $\times$ Site interaction or as some combination of these. Comparison of variance 
components seems a profitable strategy in the presence of heterogeneity of variances to detect impacts that affect spatial and/or temporal variability in the abundances of populations.

Admittedly, tests of differences between variance components are complicated by the fact that apart from estimates of the error variance, these quantities have unknown distributions (Searle et al. 1992). Our approach here was that of deriving such distributions empirically using bootstrapping procedures. This enabled us to construct bootstrap confidence intervals that could be used as the basis for formal comparisons.

\section{Specific pattern}

Changes in the structure of sessile assemblages on hard substrates near a sewage discharge have already been documented in properly designed sampling programs from both subtidal and intertidal temperate areas (Chapman et al. 1995, Roberts et al. 1998, Archambault et al. 2001).

There is a wide range of potential mechanisms that may be responsible for such patterns. A discharge of primary or secondary treated sewage can increase the amount of suspended solids in the water column and modify the rate of sedimentation. The effects of sedimentation on algae (Airoldi \& Virgilio 1998, Irving \& Connell 2002a) and sessile invertebrates (Carballo et al. 1996, Naranjo et al. 1996) have been widely reported. Sewage plumes can also reduce light by shading the bottom and this can have an influence on benthic algae (Kennelly 1989) and invertebrates (Glasby 1999, Saunders \& Connell 2001). The interactive processes of sedimentation and penetration of light on the maintenance of heterogeneity of subtidal habitats have also been pointed out recently (Irving \& Connell 2002b). Sewage can also discharge organic and inorganic compounds and the uptake of chemicals by organisms have been suggested by some authors as potentially altering the relative abundance of taxa in assemblages (Otway et al. 1996, but see Gray 2002). Clearly, the processes producing changes in assemblages at the outfall are likely to be complex and would require detailed experimental inspection.

Colpomenia sinuosa and red algae of the genus Pterocladiella and Gelidium (here grouped into the family Gelidiaceae) have been previously reported as typical of organic polluted water (Chryssovergis \& Panayotidis 1995). Extensive mats of macroalgae associated with organically enriched waters have been described for many areas (May 1985, Lopez-Gappa et al. 1990). It is reasonable to assume in this case that increasing nutrients in the vicinity of the outfall can support the standing crop observed for these algae. However, other models (e.g. the abundance of grazers and their rate of grazing, variation in salinity, etc.) remain to be explored before claiming that nutrients are the only factors controlling the abundance of such algae at a sewage outfall.

We found a significant increase in spatial variation among replicates in the total number of taxa at the outfall location compared to the control locations. This is consistent with results obtained in some other studies (Roberts 1996, Underwood \& Chapman 1996) but not with all (Roberts et al. 1998), where no significant effect of sewage effluents on the total number of taxa was found. There was no apparent difference, however, in the mean number of taxa at $I$ compared to $C s$ in the present study. For several individual taxa, in contrast, there was decreased spatial variation at the scale of replicate quadrats, in addition to Space $\times$ Time interactions at $I$ compared to $C s$. This was often accompanied by decreases in their average cover.

Changes in small-scale variability among replicates may well be a diagnostic feature for stressed assemblages. There are several reasons why small-scale variability may increase or decrease in stressed assemblages. These include changes in total cover or total number of taxa in the observation units, changes in the variance to mean ratio for particular species, or changes in taxonomic composition (Warwick \& Clarke 1993, Chapman et al. 1995). We propose that integrating univariate and multivariate approaches and distinguishing differences in means from differences in variances can bring important insights into studies of environmental impacts and, furthermore, can help generate new models to explain mechanisms causing changes in natural (and unnatural) systems.

Acknowledgements. This research was funded by the Regione Puglia (Interreg Greece-Italy project), MURST (COFIN project) and the European Union (Network of Excellence, MARBEF). P. D'Ambrosio and C. Vaglio provided invaluable assistance during field work. M. Cormaci, M. Catra, C. Longo, M. Pansini and C. Chimenz helped in identifying dubious specimens of algae, sponges and bryozoans. The final version of this manuscript greatly benefited from comments made by A. J. Underwood and 3 anonymous referees.

\section{LITERATURE CITED}

Airoldi L, Virgilio M (1998) Responses of turf-forming algae to spatial variations in the deposition of sediments. Mar Ecol Prog Ser 165:271-282

Anderson MJ (2001a) A new method for non-parametric multivariate analysis of variance. Aust Ecol 26:32-46

Anderson MJ (2001b) Permutation tests for univariate or multivariate analysis of variance and regression. Can J Fish Aquat Sci 58:626-639

Anderson MJ (2004) DISTLM v.5: a FORTRAN computer program to calculate a distance-based multivariate analysis for a linear model. Department of Statistics, University of Auckland, Auckland. Available at: 
www.stat.auckland.ac.nz/ mja/Programs.htm

Anderson MJ, Robinson J (2003) Generalised discriminant analysis based on distances. Aust NZ J Stat 45:301-318

Anderson MJ, ter Braak CJF (2003) Permutation tests for multifactorial analysis of variance. J Statist Comp Sim 73:85-113

Anderson MJ, Willis TJ (2003) Canonical analysis of principal coordinates: a useful method of constrained ordination for ecology. Ecology 84:511-525

Andrew NL, Mapstone BD (1987) Sampling and the description of spatial pattern in marine ecology. Oceanogr Mar Biol Annu Rev 25:39-90

Archambault P, Banwell K, Underwood AJ (2001) Temporal variation in the structure of intertidal assemblages following the removal of sewage. Mar Ecol Prog Ser 222:51-62

Benedetti-Cecchi L (2001) Beyond BACI: optimization of environmental sampling design through monitoring and simulation. Ecol Appl 11:783-799

Bernstein BB, Zalinski J (1983) An optimum sampling design and power tests for environmental biologists. J Environ Manage 16:335-343

Bishop M, Underwood AJ, Archambault P (2002) Sewage and environmental impacts on rocky shores: necessity of identifying relevant spatial scales. Mar Ecol Prog Ser 236: 121-128

Bray JR, Curtis JT (1957) An ordination of the upland forest communities of southern Wisconsin. Ecol Monogr 27: 325-349

Carballo JL, Naranjo SA, García-Gomez (1996) Use of marine sponges as stress indicators in marine ecosystems at Algeciras Bay (southern Iberian Peninsula). Mar Ecol Prog Ser 135:109-122

Chapman MG, Underwood AJ, Skilleter GA (1995) Variability at different spatial scales between a subtidal assemblage exposed to the discharge of sewage and two control assemblages. J Exp Mar Biol Ecol 189:103-122

Chryssovergis F, Panayotidis P (1995) Évolution des peuplements macrophytobentiques le long d'un gradient d'eutrophisation (Golfe de Maliakos, Mer Égée, Grèce). Ocean Acta 18:649-658

Clarke KR (1993) Non-parametric multivariate analyses of changes in community structure. Aust J Ecol 18:117-143

Clarke KR, Green RH (1988) Statistical design and analysis for a 'biological effects' study. Mar Ecol Prog Ser 46:213-226

Costanzo SD, O'Donohue MJ, Dennison WC, Loneragan NR Thomas M (2001) A new approach for detecting and mapping sewage impacts. Mar Pollut Bull 42:149-156

Davison AC, Hinkley DV (1997) Bootstrap methods and their application. Cambridge University Press, Cambridge

Dethier MN, Graham ES, Cohen S, Tear LM (1993) Visual versus random-point percent cover estimations: 'objective' is not always better. Mar Ecol Prog Ser 96:93-100

Eberhardt LL, Thomas MJ (1991) Designing environmental field studies. Ecol Monogr 61:53-73

Efron B, Tibshirani RJ (1993) An introduction to the bootstrap. Chapman \& Hall, New York

Fairweather PG (1991) Statistical power and design requirements for environmental monitoring. Aust J Mar Freshw Res 42:555-568

Faith DP, Humprey CL, Dostine PL (1991) Statistical power and BACI design in biological monitoring: comparative evaluation of measures of community dissimilarity based on benthic macroinvertebrate communities in Rockhole Mine Creek, Northern Territory, Australia. Aust J Mar Freshw Res 42:589-602

Gibbons JD (1982) Distribution-free methods. In: Kotz S, Johnson NL, Read CB (eds) Encyclopedia of statistical sciences, Vol 2. John Wiley \& Sons, New York, p 400-408
Glasby TM (1997) Analysing data from post-impact studies using asymmetrical analyses of variance: a case study of epibiota on marinas. Aust J Ecol 22:448-459

Glasby TM (1999) Effects of shading on subtidal epibiotic assemblages. J Exp Mar Biol Ecol 234:275-290

Glasby TM, Underwood AJ (1998) Determining positions for control locations in environmental studies of estuarine marinas. Mar Ecol Prog Ser 171:1-14

Gower JC (1966) Some distance properties of latent root and vector methods used in multivariate analysis. Biometrika 53:325-338

Gray JS (1990) Statistics and the precautionary principle. Mar Pollut Bull 21:174-176

Gray JS (2002) Biomagnification in marine systems: the perspective of an ecologist. Mar Pollut Bull 45:46-52

Green RH (1979) Sampling design and statistical methods for environmental biologist. John Wiley \& Sons, New York

Guidetti P, Fanelli G, Fraschetti S, Terlizzi A, Boero F (2002) Coastal fish indicate human-induced changes in the Mediterranean littoral. Mar Environ Res 53:77-94

Guidetti P, Terlizzi A, Fraschetti S, Boero F (2003) Changes in Mediterranean rocky-reef fish assemblages exposed to sewage pollution. Mar Ecol Prog Ser 253:269-278

Hewitt JE, Thrush SE, Cummings VJ (2001) Assessing environmental impacts: effects of spatial and temporal variability at likely impact scales. Ecol Appl 11:1502-1516

Hurlbert SH (1990) Spatial distribution of the montane unicorn. Oikos 58:257-271

Irving AD, Connell SD (2002a) Interactive effects of sedimentation and microtopography on the abundance of subtidal turfing algae. Phycologia 41:517-522

Irving AD, Connell SD (2002b) Sedimentation and light penetration interact to maintain heterogeneity of subtidal habitats: algal versus invertebrate dominated assemblages. Mar Ecol Prog Ser 245:83-91

Kedwards TJ, Maund SJ, Chapman PF (1999) Communitylevel analysis of ecotoxicological field studies. II. Replicated design studies. Environ Toxicol Chem 18:158-166

Kennelly SJ (1989) Effects of kelp canopies on understorey species due to shade and scour. J Exp Mar Biol Ecol 168:35-58

Koop K, Hutchins P (1996) Disposal of sewage to the ocean a sustainable solution? Mar Poll Bull 33:121-123

Kruskal JB, Wish M (1978) Multidimensional scaling. Sage Publications, Beverly Hills

Lardicci C, Rossi F, Maltagliati F (1999) Detection of thermal pollution: variability of benthic communities at two different spatial scales in an area influenced by a coastal power station. Mar Pollut Bull 38:296-303

Legendre P, Anderson MJ (1999) Distance-based redundancy analysis: testing multispecies responses in multifactorial ecological experiments. Ecol Monogr 69:1-24

Legendre P, Legendre L (1998) Numerical ecology, 2nd English edn. Elsevier, Amsterdam

Lopez-Gappa JJ, Tablado A, Magaldi NH (1990) Influence of sewage pollution on a rocky intertidal community dominated by the mytilid Brachidontes rodriguezi. Mar Ecol Prog Ser 63:163-175

Manly BFJ (1997) Randomization, bootstrap and Monte Carlo methods in biology. Chapman \& Hall, London

May V (1985) Observations on algal floras close to two sewage outfall. Cunninghamia 1:385-394

McArdle BH, Anderson MJ (2001) Fitting multivariate models to community data: a comment on distance-based redundancy analysis. Ecology 82:290-297

Naranjo SA, Carballo JL, García-Gomez (1996) Effects of environmental stress on ascidian populations in Algeciras Bay (southern Spain): possible marine bioindicators? Mar 
Ecol Prog Ser 144:45-71

Neter J, Kutner MH, Wasserman W, Nachtscheim CJ (1996) Applied linear statistical models. McGraw-Hill/Irwin, New York

Noether GE (1985) Nonparametric confidence intervals. In: Kotz S, Johnson NL, Read CB (eds) Encyclopedia of statistical sciences, Vol 6. John Wiley \& Sons, New York, p 319-324

Osenberg CW, Schmitt RJ (1996) Detecting ecological impacts caused by human activities. In: Schmitt RJ, Osenberg CW (eds) Detecting ecological impacts: concepts and applications in coastal habitats. Academic Press, San Diego, p 3-16

Osenberg CW, Schmitt RJ, Holbrook SJ, Abu-Saba KE, Flegal R (1994) Detection of environmental impacts: natural variability, effects size, and power analysis. Ecol Appl 4:16-30

Otway NM, Gray CA, Craig JR, McVea TA, Ling JE (1996) Assessing the impacts of deep-water sewage outfall on spatially- and temporally-variable marine communities. Mar Environ Res 41:45-71

Pearson TH, Rosenberg R (1978) Macrobenthic succession in relation to organic enrichment and pollution of the marine environment. Oceanogr Mar Biol Annu Rev 16:229-311

Phillips DJH (1978) The use of biological indicator organisms to quantitate organochlorine pollutants in aquatic environments - a review. Environ Poll 16:167-229

Roberts DE (1996) Effects of the North Head deep-water sewage outfall on nearshore coastal reef macrobenthic assemblage. Mar Pollut Bull 33:303-308

Roberts DE, Smith A, Ajani P, Davis AR (1998) Rapid changes in encrusting marine assemblages exposed to anthropogenic point-source pollution: a 'Beyond BACI' approach. Mar Ecol Prog Ser 163:213-224

Saunders RJ, Connell SD (2001) Interactive effects of shade and surface orientation on the recruitment of spirorbid polychaetes. Aust Ecol 26:109-115

Searle SR, Casella G, McCulloch GE (1992) Variance components. John Wiley, New York

Smith A, Ajani PA, Roberts DE (1999) Spatial and temporal variation in fish assemblages exposed to sewage and implications for management. Mar Environ Res 47: 241-260

Smith EP, Pontasch KW, Cairns J (1990) Community similarity and the analysis of multispecies environmental data: a unified statistical approach. Water Res 24:507-514

Stewart-Oaten A, Bence JR (2001) Temporal and spatial variation in environmental impact assessment. Ecol Monogr 71:305-339

Stewart-Oaten A, Murdoch WW, Parker KR (1986) Environ-

Editorial responsibility: Tony Underwood (Contributing Editor), Sydney, Australia mental impact assessment: 'pseudoreplication' in time? Ecology 67:929-940

Taylor LR (1961) Aggregation, variance and the mean. Nature 189:732-735

ter Braak CJF (1986) Canonical correspondence analysis: a new eigenvector technique for multivariate direct gradient analysis. Ecology 67:1167-1179

Terlizzi A, Fraschetti S, Guidetti P, Boero F (2002) The effects of sewage discharge on shallow hard substrate sessile assemblages. Mar Pollut Bull 44:544-550

Underwood AJ (1991) Beyond BACI: experimental designs for detecting human environmental impacts on temporal variations in natural populations. Aust J Mar Freshw Res 42: 569-587

Underwood AJ (1992) Beyond BACI: the detection of environmental impacts on populations in the real, but variable world. J Exp Mar Biol Ecol 161:145-178

Underwood AJ (1993) The mechanisms of spatially replicated sampling programmes to detect environmental impact in a variable world. Aust J Ecol 18:99-116

Underwood AJ (1994) On beyond BACI: sampling designs that might reliably detect environmental disturbances. Ecol Appl 4:3-15

Underwood AJ (1996) Spatial patterns of variability in density of intertidal populations. In: Floyd RB, Sheppard AW, De Barro PJ (eds) Frontiers of population ecology. CSIRO Publishing, Melbourne, p 369-389

Underwood AJ (1997) Experiments in ecology: their logical design and interpretation using analysis of variances. Cambridge University Press, Cambridge

Underwood AJ, Chapman MG (1996) Subtidal assemblages on rocky reefs at a cliff-face sewage outfall (North Head, Sydney, Australia): What happened when the outfall was turned off? Mar Pollut Bull 33:293-302

Underwood AJ, Chapman MG (1998) Spatial analyses of intertidal assemblages on sheltered rocky shores. Aust J Ecol 23:138-157

Underwood AJ, Peterson CH (1988) Towards an ecological framework for investigating pollution. Mar Ecol Prog Ser 46:227-234

Warwick RM, Clarke KR (1993) Increased variability as a symptom of stress in marine communities. J Exp Mar Biol Ecol 172:215-226

Warwick RM, Platt HM, Clarke KR, Agard J, Gobin J (1990) Analysis of macrobenthic and meiobenthic community structure in relation to pollution and disturbance in Hamilton Harbour, Bermuda. J Exp Mar Biol Ecol 138:119-142

Winer BJ, Brown DR, Michels KM (1991) Statistical principles in experimental designs, 3rd edn. McGraw-Hill, Sydney

Submitted: February 14, 2003; Accepted: September 1, 2004 Proofs received from author(s): February 19, 2005 